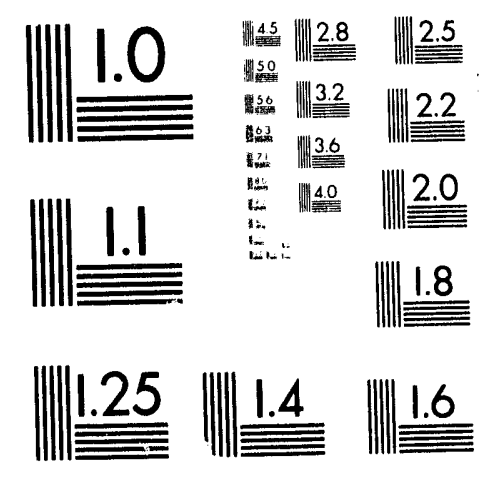



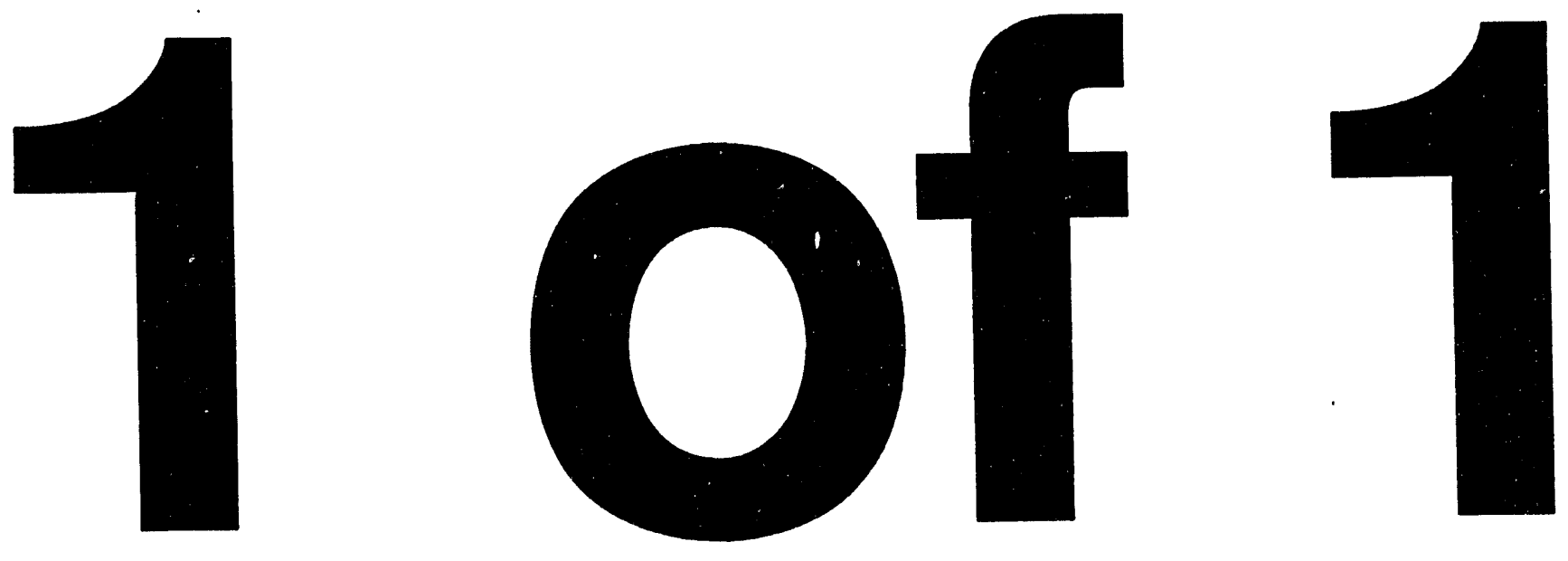
General Motors Corporation and

Pacific Northwest Laboratory Staff

Exchange: Inspection of Case Hardened

Steels and Metal-Matrix Composites

M. S. Good

D. D. Rogers ${ }^{(a)}$

October 1993

Prepared for

U.S. Department of Energy

under Contract DE-AC06-76RLO 18306

Pacific Northwest Laboratory

Richland, Washington 99352

(a) Saginaw Division

General Motors Corporation

Saginaw, Michigan 48601-9494 


\section{General Motors Corporation and Pacific Northwest Laboratory Staff Exchange: Inspection of Case Hardened Steels and Metal-Matrix Composites}

Staff exchanges, such as the one described in this report, are intended to facilitate communication and collaboration among scientists and engineers at Department of Energy (DOE) laboratories, in U.S. industry, ant academia. Funding support for these exchanges is provided by the DOE, Office of Energy Research, Laboratory Technology Transfer Program. Funding levels for each exchange typically range from $\$ 20,000$ to $\$ 40,000$. The exchanges offer the opportunity for the laboratories to transfer technology and expertise to industry, gain a perspective on industry's problems, and develop the basis for further cooperative effors through Cooperarive Research and Development Agreements (CRADAs) or other mechanisms.

Information in this report on the staff exchange of Pacific Northwest Laboratory (PNL) staff with General Motors (GM) Corporation includes the purpose and objectives, a summary of activities, significant accomplishments, significant problems, industry benefits realized, recommended follow-on work and potential benefits from that work, and three appendixes. Appendix A is a description of ultrasonic backscatter technology and its applications to the two nondestructive inspection interests defined by GM. Appendix B is a list of key contacts and the schedule of activities pertaining to the staff exchange. Appendix $\mathrm{C}$ is an article from American Society for Metals News relating to sensor needs.

\section{Purpose/Objective}

The objectives of this project were as follows:

- for PNL staff to present technology to GM staff on nondestructive measurement of hardened steel components and uniformity of particle dispersal in metal-matrix composites for evaluation for possible application in GM's manufacturing processes

- for GM staff to discuss with PNL staff common manufacturing processes, metallurgy, and flaw criteria for hardening of various components and manufacturing of metal-rnatrix composites

- to provide an initial step in building a long-term collaborative relationship between PNL and GM.

\section{Summary of Activities Performed}

The Staff Exchange Program between PNL and GM began September 1992. Ultrasonic backscatter was the primary nondestructive method employed by PNL to measure hardness depth and to qualitatively examine particle distribution. (See Appendix A for a description of the signal source for both applications and images demonstrating the capability of the technology.) To facilitate 
interaction, a portable demonstration unit of the nondestructive measurement technology was completed and numerous GM staff were invited to contact Mr. Dennis D. Rogers, Saginaw Division, $\mathrm{GM}$, to coordinate visits.

The staff exchange of Dr. Morris Good from PNL to GM occurred during three weeks interspersed from September 28 to November 4, 1992. During the program, Dr. Good met with GM personnel, conducted application experiments, and met with U.S. Department of Energy (DOE) and GM personnel (Appendix B). These accomplishments satisfied the first two objectives in the Field Work Proposal.

As part of the staff exchange, Dr. Good viewed GM production facilities and listened to GM personnel describe their testing needs. A PNL-developed prototype unit for measuring hardness depth was demonstrated. This demonstration permitted GM personnel to directly cbserve measurements on a number of cylindrical components such as pump shafts, rods, and axles. GM personnel, thereby, gained insight to the robustness of the technology to potentially operate on the production floor.

\section{Plant Tours}

Dr. Good toured the Flint Transmission Complex, Flint, Michigan, and plants 2, 3, and 5 of Saginaw Division, GM, Saginaw, Michigan. During these tours, Dr. Good interacted diractly with plant personnel.

\section{Experiments}

Three application experiments were performed at Saginaw Division, GM. In experiment 1, staff examined induction hardened piston rods used in steering linkages (a nominal hardness depth of 0.05 inch). Seven batches of rods were inspected in a blind test with selected variations such as hardness depth and the length of unhardened regions. The conclusion was that the ultrasonic measurements correlated well with relative changes in hardness depth and accurately defined the end of hardened regions.

In experiment 2, staff examined induction hardened pump shafts ranging in hardness depth from 0.02 inch to 0.06 inch. Data from a sample with a final ground surface finish indicated that accurate measurements were possible for hardness depths greater than 0.04 inch. The as-heat-treated surface condition, however, hindered application of a simple threshold algorithm. A recommendation was to either measure hardness depth after the final grinding operation or to improve the surface condition prior to hardening.

In experiment 3, staff evaluated front-wheel-drive axles induction hardened between 0.15 inch to 0.21 inch. The 0.21 -inch value was the deepest hardness depth examined to date. Measurement error was less than 3 percent for nine samples which had as-heat-treated surfaces and consisted of three different steel heats. 


\section{Meeting Between DOE and GM Personnel}

A meeting between DOE and GM personnel was held at the Annual Automotive Technology Development Contractors' Coordination Meeting. At the request of DOE, Dr. Good demonstrated the ultrasonic measurement technology for Dr. Ted Vojnovich of the Office of Energy Research, Laboratory Technology Transfer (ER-LTT) program and Dr. Sidney Diamond of DOE's Office of Transportation Materials. Dr. Diamond expressed interest in the technology from the perspective of producing lighter-weight automotive vehicles.

The enthusiasm of GM personnel was also clearly evident, when Mr. Dennis D. Rogers traveled from Saginaw to Dearborn, Michigan, to discuss with DOE GM's interest in expanding the technology evaluation toward process control on the production floor. Mr. Rogers stated that the technology appeared to be very useful and that GM desired to initiate a more thorough evaluation of it. The priority of the metal-matrix application was lower, since metal-matrix component production had been delayed several years by Saginaw Division. PNL, however, did demonstrate to many GM staff the ability to produce ultrasonic images that accurately map particle distribution in a metal-matrix composite.

\section{Significant Accomplishments}

The staff exchange of Dr. Good of PNL to GM promoted significant interaction between industry and DOE. A small follow-on Cooperative Research and Development Agreement (CRADA) between PNL and GM has been finalized. GM's contribution to this CRADA is $\$ 87,000$, including $\$ 47,000$ in direct funds. This compares to a DOE contribution of $\$ 50,000$ to the CRADA. A much larger follow-on cooperative research and development program has also been proposed for funding to both the DOE ER-LTT program and the Advanced Research Projects Agency (ARPA), Technology Reinvestment Program (TRP). Thus, the third objectivo of forming a long-term working relation between PNL and GM is progressing.

Although GM is the primary industry participant in these proposals, the larger proposals include several other potential industry users (including Chrysler Corporation) and a potential vendor of the technology. Thus, the staff exchange provided a means to generate significant industry interest in the nondestructive measurement technology.

Industry is interested in the technology because of the high potential for industrial process cost savings. Both the potential benefits of the technology and its measurement efficacy were demonstrated in the staff exchange. The results of the ultrasonic measurements of the technology correlated well with relative changes in hardness depth and accurately defined the end of hardened regions. The measurement error on heat-treated axles was less than 3 percent for nine samples, which had as-heattreated surfaces and consisted of three different steel heats.

Automotive personnel have estimated that a 10-percent mass reduction of hardened components might result from improved designs and improved process control during fabrication. This mass reduction and significant reductions in both heat treating and destructive testing costs, could result from the widespread use of the metering technology. 


\section{Significant Problems}

No problems occurred during the staff exchange. Initially both GM and PNL had reservations on how beneficial the staff exchange would be. During the 3 weeks, however, GM and PNL personnel freely exchanged information and concluded that the time and effort were much more beneficial than had been envisioned by either. If a problem was listed, it was that the staff exchange did not last longer.

\section{Industry Benefits Realized}

Heat-treating processes harden steel components to specified depths and currently requires statistical testing by destructive analysis (sectioning selected pieces). Thus, components are destroyed, feedback is slow ( 30 minutes or more for axles), and measurement accuracy is inconsistent and subjective. The demonstrated technology is nondestructive, accurate, and is expected to provide feedback within seconds of completing the hardening process. Saginaw Division, GM, estimates tens of millions of dollars could be saved if a broad and generic hardness depth meter was commercially available.

\section{Recommended Follow-On Work}

Three recommendations for follow-on work resulted from the staff exchange. One was that a CRADA project be developed with the objective of evaluating the technology on the production floor of Saginaw Division, GM. This recommendation is being addressed through a small CRADA that was initiated in August 1993, between GM and PNL with funding support from the DOE ER-LTT program. A second recommendation is to approach U.S. manufacturers who harden steel components and the heat-treating industry to coalesce industry's needs concerning nondestructive measurements of hardness depth. The third recommendation is to facilitate the commercialization of the instrumentation by technology transfer to an instrument vendor. These last two recommendations are consistent with the objectives of the larger follow-on CRADA proposals involving multiple users and a potential vendor of the technology that were submitted to ER-LTT and ARPA.

\section{Potential Benefits from Pursuing Follow-On Work}

Hardening is performed for numerous steel components in manufacturing industries. It is a very costly process that could potentially benefit from the use of nondestructive evaluation technology, both for improved process control and for reducing the costs of destructive testing. However, U.S. companies have not been able to justify research and development funding to develop the technology. U.S. manufacturing industries should be approached and brought into a much more extensive CRADA whereby targeted component classes from industry are formed, research and development performed to address nondestructive measurements for process control, prototype systems fabricated and evaluated by industry, and the technology transferred to an instrument vendor for commercialization. This work, if funded, would coalesce industry needs and provide them with commercially available instrumentation. 
U.S. manufacturing will benefit by improving productivity, making higher quality machinery, and producing components with higher strength with reduced mass. U.S. automotive manufacturers export components to foreign automotive companies, and improved quality at a lower manufactured cost will enhance the potential to increase U.S. exports of manufactured machinery or components, help regain our national reputation for quality, and thus, create and retain U.S. jobs. As stated in ASM News, Vol. 23, No. 4, April 1993, the ASM Heat Treating Steering Panel Research and Development Committee listed improved process controls and consistency as one of the four most needed advancements over the next 5 to 10 years for the heat treating industry. (See Appendix C for news article.) ${ }^{\text {(a) }}$ This technology will provide process control to the hardening process and permit nondestructive inspection.

(a) Reprinted by permission of ASM International from ASM News, Vol.23, No. 4, April 1993, ASM International, Materials Park, Ohio. 
Appendix A

Applications of Ultrasonic Backscatter 


\section{Applications of Ultrasonic Backscatter}

Applications of the refined technology may improve manufacturing quality by providing inspection feedback. Two such applications include hardened steel components and metal-matrix composites.

\section{Hardness Depth}

Machinery fabrication from automobiles to sewing machines use heat treatment to place a hard, ware-resistant surface on a tough but softer steel core. An example is a rod used in General Motors automotive steering linkage. The rod is hardened except for the ends where it is left soft to increase toughness for enduring a press fit. The hardness depth photograph (Figure A.1) shows a transition from a 0.05-inch-deep hardness depth to no depth at the rod end at the right. This is a crosssectional view with depth a long the vertical axis and axial position along the horizontal axis. Note the demarkation between the hardness layer and core on the left side of Figure 1 and how the hardness depth becomes less towards the rod end until it reaches the surface. Interesting feedback measurements would include hardness depth along the hardened region of the rod and the rod length at both ends which are unhardened. See also Figure A.2. (A \$137K-Total Resources FY 1993 CRADA has been finalized with GM concerning quantitative measurement of hardness depth August 1993. A \$2.6M-Total Resources FY 1994-1996 CRADA was also proposed with GM, Chrysler, and TRW as participants, which was much broader in scope than the first CRADA.)

\section{Metal Matrix Composites}

New exotic materials such as metal-matrix composites are being used for improved performance. An example is a lightweight prop shaft for automotive drive trains. A component might use a base aluminum alloy as a matrix with a suspension of silicon carbide particles. A problem is that the composite is not weldable. One solution is to design in a transition to the base aluminum alloy near the end of the extruded tube. Two interesting feedback measurements include the distribution uniformity of silicon carbide particles in the composite and the demarkation between the pure alloy and the composite.

The metal-matrix composites photograph Figure A.3 shows an ultrasonic image revealing a cross section of a tube wall over the transition. The spatial scale of the two axes in the image are quite different, .02 inch and 9 inches. The vertical axis is depth with the outer surface of the tube at the top ( 0.0 inch) and the inner surface of the tube wall at the bottom ( 0.2 inch). The horizontal axis is axial position along the tube which spanned 9 inches.

The signal is initially very strong at the exterior surface. As the wave passes through the metal, wavelets are scattered away from the wave front and result in a nrogressive weakening of the wave front. Thus, yellows give way to blues from the top to the bottom in the image. The outer and inner surfaces are visible since they are a higher amplitude signal source than that of the microstructure. 
Progressing axially down the shaft, a tapered region is visible from 3.5 to 5.5 inches. The aluminum alloy produces a reference amplitude response and is displayed axially from 0.0 to 3.5 inches. Since the silicon carbide particles are sources of increased scatter, the metal-matrix composites material is indicated by increased amplitude and begins at 3.5 inches at the inner surface. At 5.5 inches the tube wall is essentially all composite material. The wedge shape and position correlated very well with the destructive micrographs. 
$\begin{array}{ll}0 \\ -6 & 0 \\ 0 & 0 \\ 0 & 0\end{array}$

$-75$

$0 \%$

31

S.

$\therefore$

(6)

i.

(b)

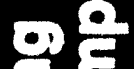

5

$\Rightarrow$

36

$\Rightarrow$

3

co

궁

61

9

(ii) 9

$\because \frac{2}{2}$

a.

ב

(19)

(1)

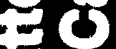

7 .

$6 \%$

$-3=8$

o $=5$

(.) 65

(i) $6=$

()

है 항

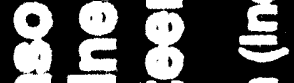

i2 $=$

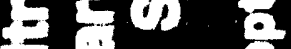

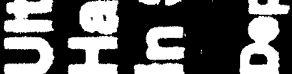

9

82

8.8

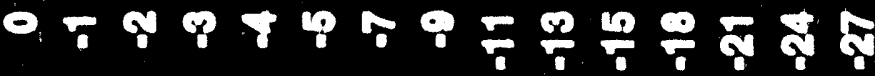

E3

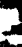

7

-

$\exists$

5

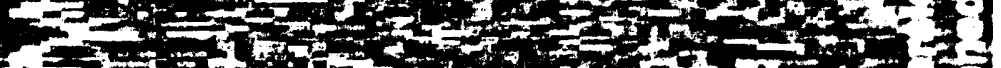

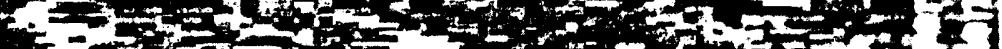

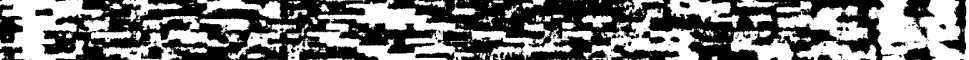

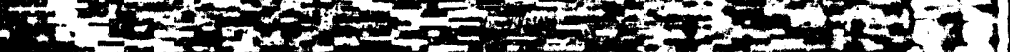

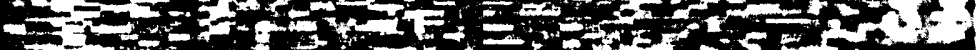

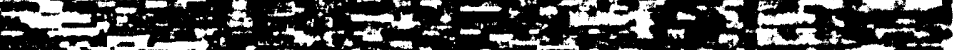

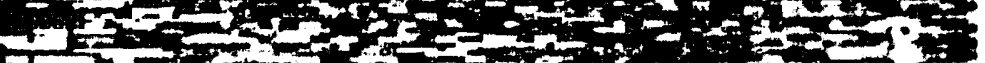

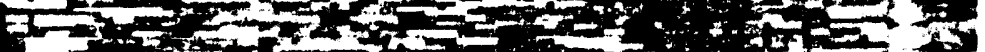

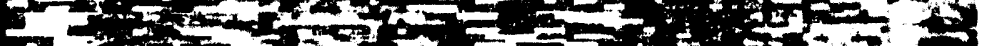

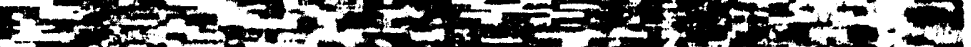

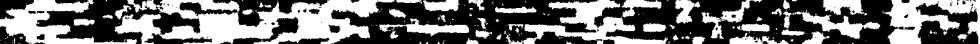

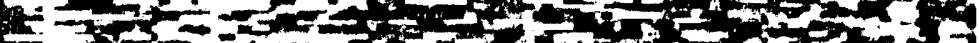

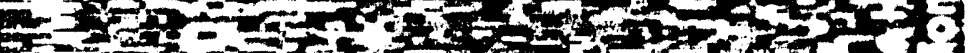

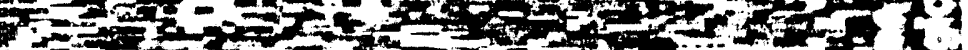

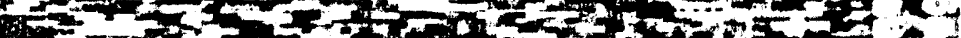

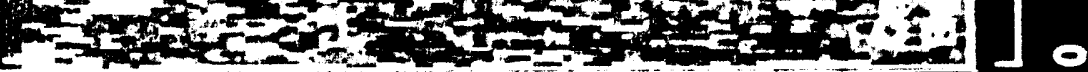

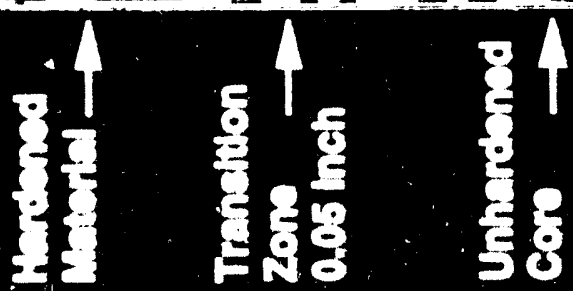




\section{Ultrasonic Backscatter Image Demonstrating Capability to Profile Hardness Depth (Piston Rod Used in Steering Linkages)}

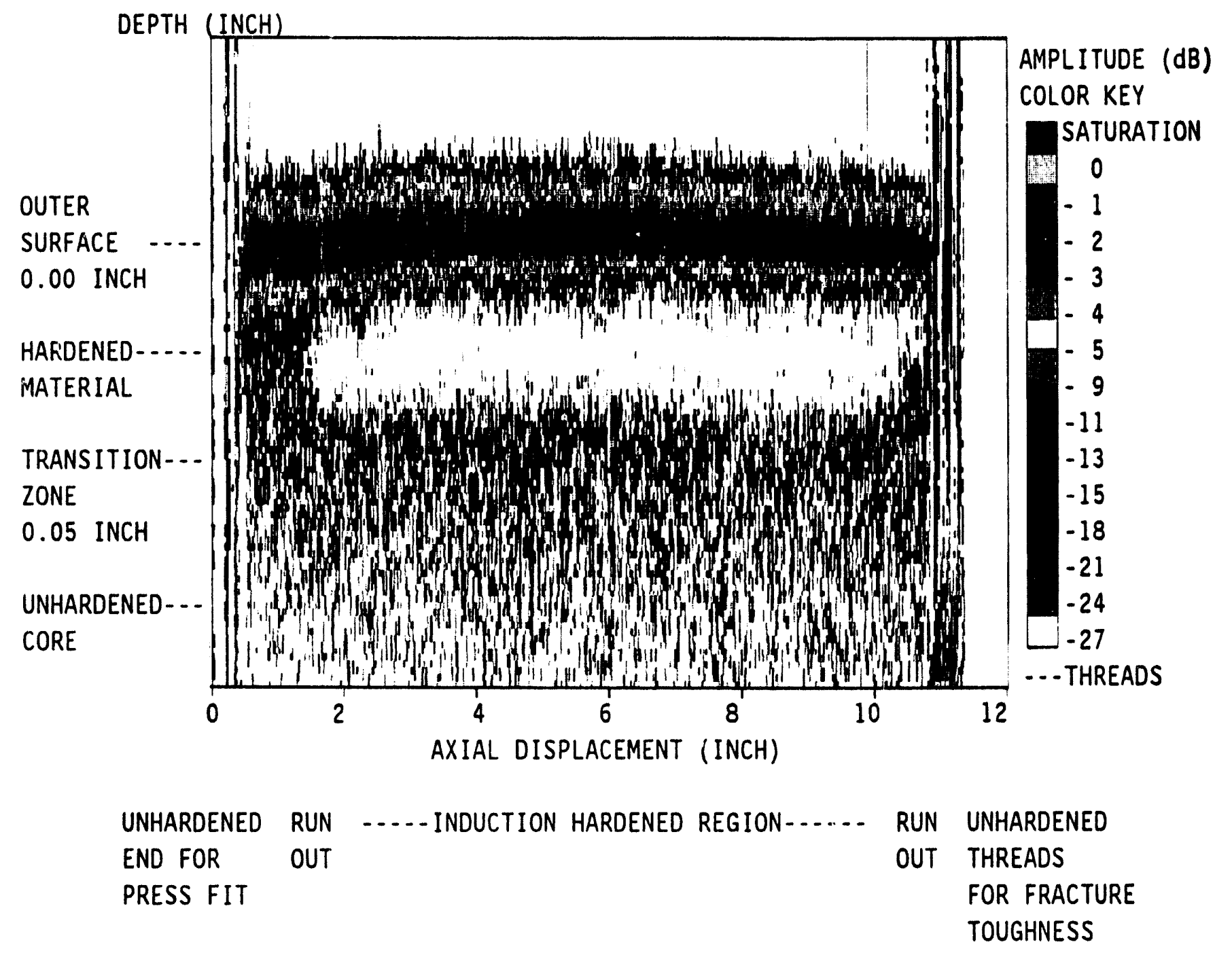

\section{PISTON ROD}

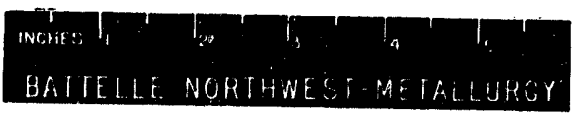

Figure A.2 


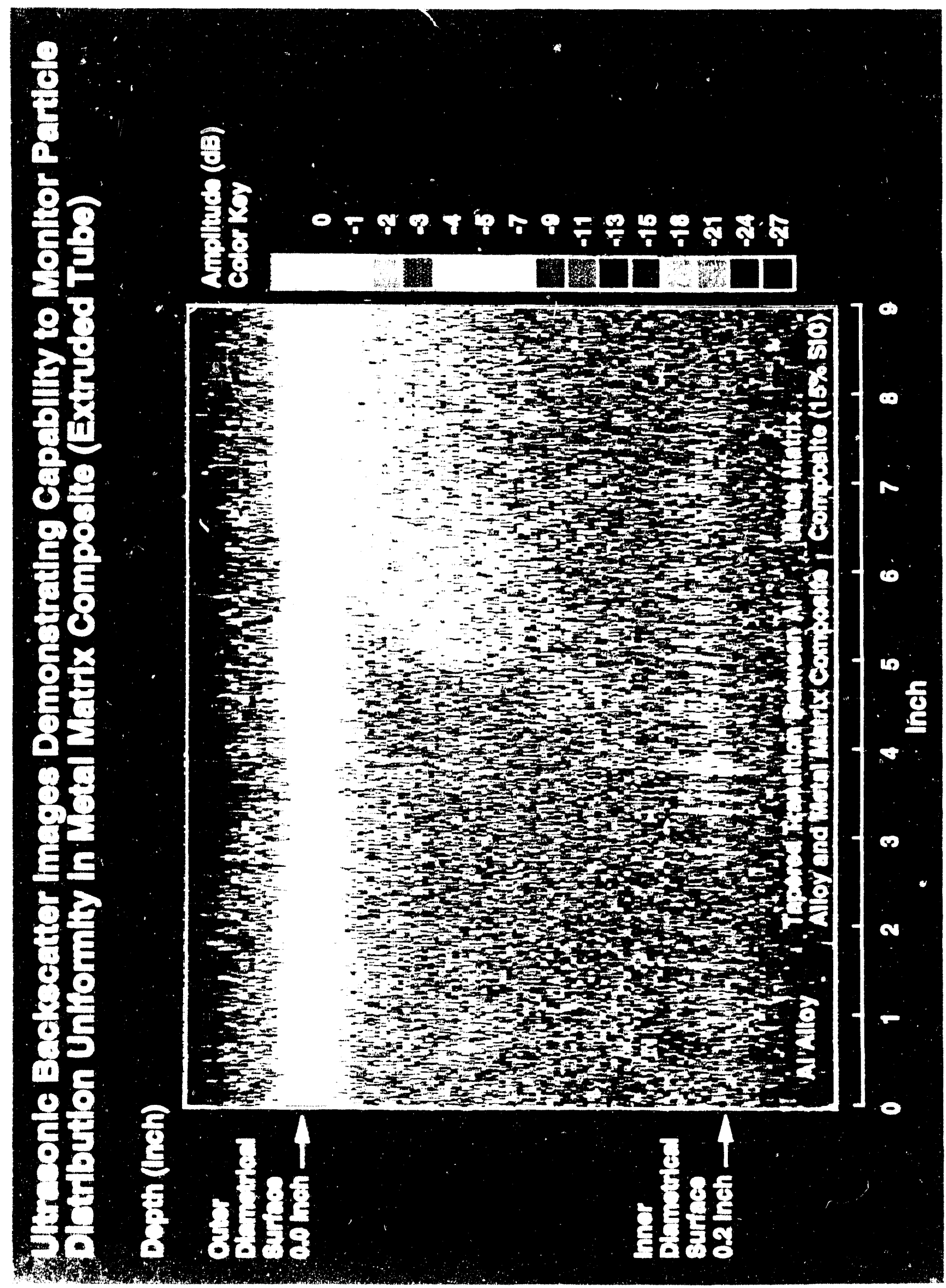




\section{Appendix B}

List of Key Contacts and Schedule of Activities for Staff Exchange 


\section{Key Contacts}

Contact

Dale K. Benedict

Saginaw Division

General Motors Corporation

Saginaw, Michigan

Jeffery Berges

GM Powertrain Division

General Motors Corporation

Flint, Michigan

Virender N. Choudhri

Plant 2 Metallurgist

Saginaw Division

General Motors Corporation

Saginaw, Michigan

Sidney Diamond, Ph.D.

Program Manager

Office of Transportation Materials

Department of Energy

Washington, D.C.

\section{Mo Fetouh}

Advance Engineering Staff

General Motors Technical Center

General Motors Corporation

Warren, Michigan

Richard A. Greketis

Supt. Central Services - Plant 7

Saginaw Division

General Motors Corporation

Saginaw, Michigan

Y. Helen Gu, Ph.D.

Materials Research Engineer

General Motors Gear Center

General Motors Corporation

Romulus, Michigan

William M. Jones

Senior Metallurgical Engineer

GM Powertrain Division

General Motors Corporation

Flint, Michigan
Comments

Lead engineer in the fabrication of hypoid gears

Interested in powertrain gears

Lead engineer in making pitman shaft gears and rack piston nuts; provided tour of plant 2

Became intarested in hardness depth measurement beceuse of potential to reduce component mass by $10 \%$

Interested in a newly designed connecting rod

Interested in application of ultrasonic technology to piston rods used in steering linkages

Interested in hardness depth measurements of transmission gears; provided interface to GM Powertrain Division

Interested in hardness depth measurement of powertrain gears

B.1 
Bruce A. Landskroener

Asst. Plant Metallurgist - Plant 5

Saginaw Division

General Motors Corporation

Saginaw, Michigan

Tom Lynes

Plant Metallurgist - Plants 4 \& 5

Saginaw Division

General Motors Corporation

Saginaw, Michigan

Richard W. Marczewski

Advanced Engineering Staff

Advanced Manufacturing Engineering

General Motors Corporation

Warren, Michigan

\section{Dennis D. Rogers}

Staff Materials Engineer

Saginaw Division

General Motors Corporation

Saginaw, Michigan

David L. Timma

Plant 3 Metallurgist

Saginaw Division

General Motors Corporation

Saginaw, Michigan

Ted Vojnovich

Program Manager

Office of Energy Research

Department of Energy

Washington, D.C.

Al Young

Metallurgist

Saginaw Division

General Motors Corporation

Saginaw, Michigan
Interested in application of ultrasonic technology to front-wheel-drive axles

Interested in application of ultrasonic technology to front-wheel-drive axles

Lead GM team that initiated contact with PNL

Key contact at Saginaw Division, GM, and host during staff exchange; interested in an assortment of components made by Saginaw Division, GM; worked with PNL to form Joint Work Statement of CRADAs

Interested in hardness depth measurements of pump shafts, rotors, and assortment of parts

DOE Manager of PNL-GM Staff Exchange Program; DOE official interested in transferring nondestructive hardness depth mensurement technology to industry

Key metallurgist who directed most of the destructive tests that were compared to the ultrasonic measurements 


\section{Schedule of Activities}

Date Activity

\footnotetext{
September 28 - Arrive at Saginaw Division, GM

September 29 - 10:00 - meet with David Timma and tour Plant 3, Saginaw, Michigan 1:00 - meet with Dale Benedict, Saginaw, Michigan

September 30 - 1:00 - meet with Virender N. Choudhri and Dennis Rogers and tour Plant 2, Saginaw, Michigan

October 1 - Continue work at Saginaw, Michigan

October 2 - 10:00 - meet with James S. Coryell, Saginaw, Michigan, concerning metal-matrix composite inspection

October 5 - 9:00 - meet with Ali Badawy, Saginaw, Michigan

9:30 - meet with Y. Helen Gu, Ph.D. at Saginaw, Michigan

4:00 - leave Saginaw Division, GM

October 9 - Arrive at Saginaw Division, GM

October 13 - 10:00 - meet with Tom Lynes, Bruce Landskroener, and Dennis Rogers and tour Plant 5 , Saginaw, Michigan

1:00 - meet with William Jones, Jeffery Berges, and Helen Gu and tour Plant 5, GM Powertrain, Flint, Michigan

October 14 - 10:00 - demonstrate PNL hardness depth meter to Bruce Landskroener of Plant 5, Saginaw, Michigan

October 15 - 10:30 - demonstrate PNL hardness depth meter to Richard Greketis, Plant 7, Saginaw, Michigan

October $16-1: 00$ - Make presentation at Saginaw Division, Saginaw, Michigan

4:00 - leave Saginaw Division, GM

November 2 - Arrive at Saginaw Division, GM

November 3 - 10:00 - travel to Annual Automotive Technology Development Contractors' Coordination Meeting, Dearborn, Michigan, and meet with Dennis Roger, GM; Ted Vojnovich, DOE; Bruce Harrer, PNL

12:00 - demonstrate hardness depth measurement to Ted Vojnovich and Sidney Diamond, DOE; and Bruce Harrer, PNL at Annual Automotive Technology Development Contractors' Coordination Meeting, Dearborn, Michigan

5:00 - travel back to Saginaw, Michigan

November 4 - 1:00- demonstrate hardness depth measurement of front-wheel-drive axles to Tom Lynes of Plant 5 and Dennis Rogers, Saginaw, Michigan

November 5 - Leave Saginaw, Michigan

December 1 - 1:30 - Give status report of staff exchange to PNL personnel at PNL, Richland, Washington.

December 8 - Submitted Draft CRADA, PNL No. 023, Evaluation of a Case Depth Laboratory Instrument to GM

February 24 - Mr. John J. Sheridan and Dr. Nicholas A. Weil, National Center for Manufacturing Sciences, visit PNL to review nondestructive hardness depth measurement technology

April 23 - Submitted "spinoff" CRADA proposal to DOE, Multiple Meters for Nondestructively Measuring the Hardness Depth of Hardened Steel Components

July 23 - GM submitted "spinoff" TRP proposal to ARPA, Multiple Meters for Nondestructively Measuring the Hardness Depth of Hardened Steel Components
} 


\section{Appendix C}

American Society for Metals News Article 


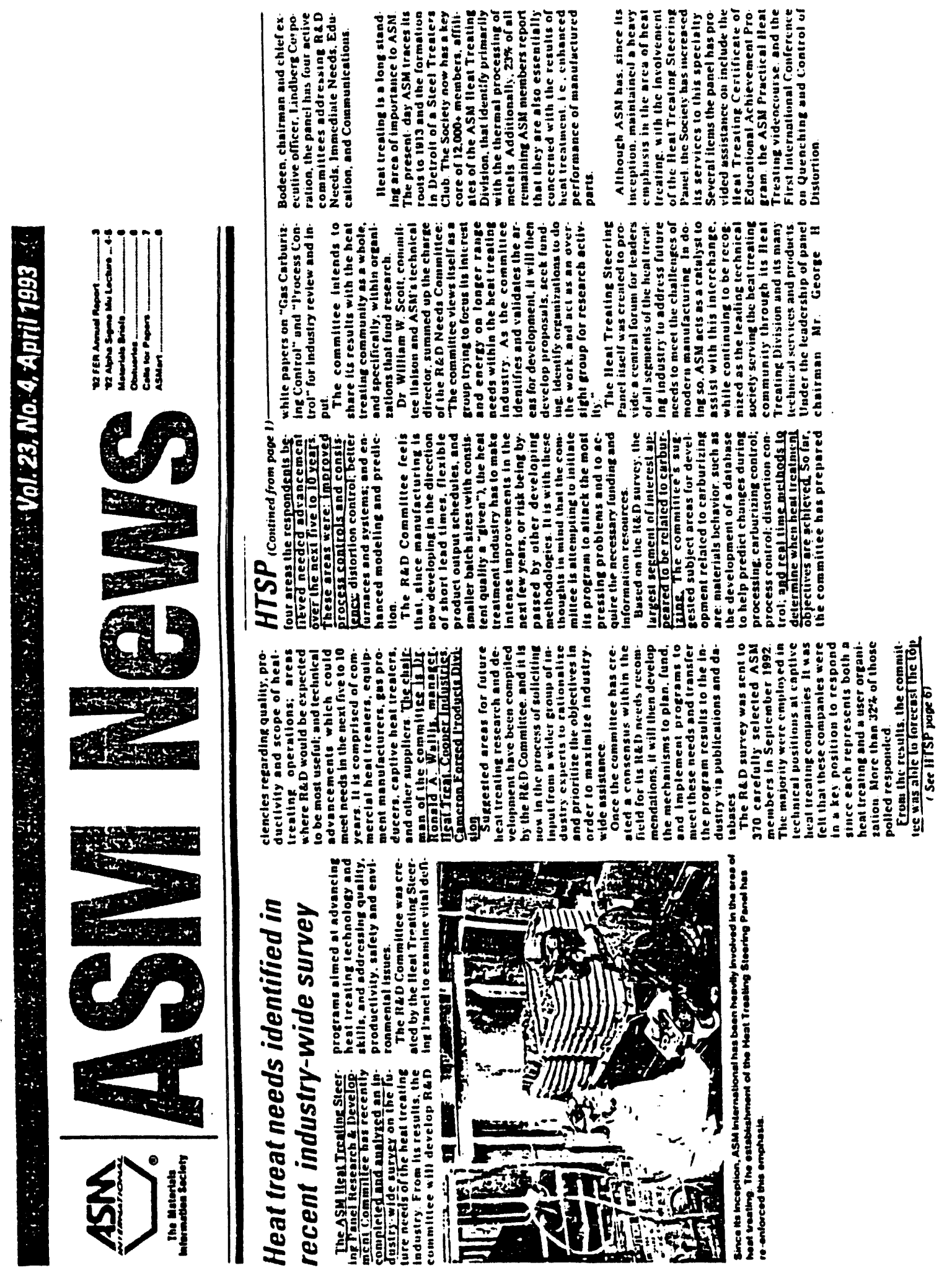

C. 1 


\section{Distribution}

No. of

Coples

\section{OFFSITE}

2 DOE Office of Scientific

and Technical Information

M. Abbot

Laboratory Management Division

U.S. Department of Energy

Office of Energy Research

Forrestal Building (ST-311)

1000 Independence Avenue, SW

Washington, D.C. 20585

S. Diamond

U.S. Department of Energy

Office of Transportation Materials

Forrestal Building (CE-34)

1000 Independence Avenue, SW

Washington, D.C. 20585

2 Y. H. Gu

Materials Research Engineer

General Motors Gear Center

General Motors Corporation

37350 Ecorse Road

Romulus, MI 48174-1376

R. W. Marczewski

Advanced Engineering Staff

Advance Manufacturing Engineering

General Motors Corporation

Technology Exchange for Auto Manufacturing

6490 E. 12 Mile Road

Warren, MI 48090-9000
No. of

Copies

3 D. D. Rogers

Staff Materials Engineer

Saginaw Division

General Motors Corporation

3900 Holland Road

Saginaw, MI 48601-9494

T. Vojnovich

Technical Program Manager

ER Laboratory Technology Transfer

Program

U.S. Department of Energy

Office of Energy Research

Forrestal Building (ST-311)

1000 Independence Avenue, SW

Washington, D.C. 20585

A. Zerega

Laboratory Management Division

U.S. Department of Energy

Office of Energy Research

Forrestal Building (ST-311)

1000 Independence Avenue, SW

Washington, D.C. 20585

\section{ONSITE}

DOE/Richland Operations Office

G. M. McClure

K8-50

11 Pacific Northwest Laboratory

D. M. Boyd

M. Clement

K5-10

M. S. Good

K1-17

B. J. Harrer (2)

K5-26

Publishing Coordination

Technical Report Files (5) 

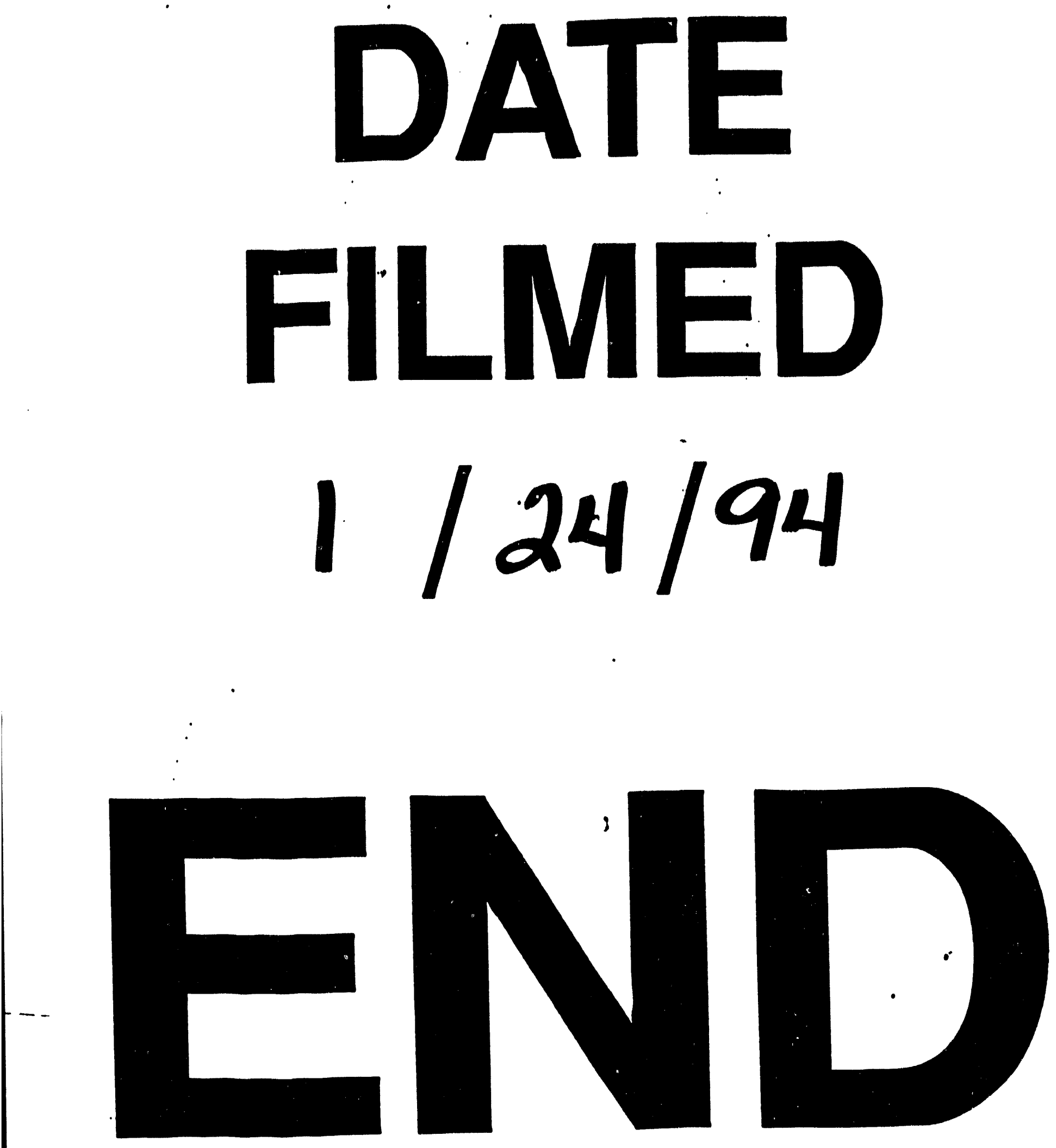
